\title{
Mechanical Properties of the Esophageal Wall
}

\author{
Raj K. Goyal, Piero Biancani, Aris Phimitips, and Howard M. Spiro \\ From the Department of Internal Medicine, and the Department of Engineering \\ and Applied Science, Yale University, New Haven, Connecticut 06510
}

A B S T R A C T Pressure-diameter curves of the esophagus were obtained to define its mechanical properties. The mucosal contribution to the strength of the esophagus was negligible until the outer diameter almost doubled, suggesting that small intraluminal pressures are held by the muscle layer alone. For larger deformations mucosal contribution increased and at failure the mucosa held over one-half of the failure pressure of the esophagus.

The paths followed during loading and unloading are different and exhibit hysteresis. They are influenced by the rate of pressure change, being more compliant for low rates of pressure change. They are influenced by the history of loading, being different for successive loadingunloading cycles. If enough loading-unloading cycles are repeated a stable loop is reached, which does not change thereafter.

Both the mucosa and the whole esophagus show increasing stiffness with increasing pressure. This behavior can be represented by a simple exponential relationship. However, at rapid rates of pressure increases, the esophageal muscles produce sigmoid loading curves, which gradually become exponential when repeating loading.

\section{INTRODUCTION}

An understanding of the mechanical characteristics of the materials constituting the walls of the gastrointestinal tract is necessary to evaluate its normal behavior as well as conditions of failure, to understand the mechanics of bolus transport, and to develop suitable biomaterials for replacement, when needed. Despite a renewed interest in biomechanics, as evidenced by recent studies on the mechanical properties of blood vessels (1-3), lungs $(4)$, muscles $(5,6)$, tendons $(7,8)$, skin $(9)$, and many other organs and tissues (10), little information is available on the mechanical properties of the gastro-

Dr. Goyal's present address is Department of Medicine, Baylor College of Medicine, Houston, Tex.

Received for publication 24 June 1970 and in revised form 26 February 1971. intestinal tract. The few studies on the pressure volume relationship, as for example of colon (11), fall short in defining the mechanical behavior of this organ. This is because the volume of the balloon used in such studies bears no constant relationship to the deformation or changes in the diameter.

The purpose of this study was to define some of the mechanical characteristics of the esophageal wall, using the rat as an experimental model.

\section{METHODS}

Different experiments (over 200 in all) were performed on small groups of rats of the Sprague-Dawley strain, weighing $200-300 \mathrm{~g}$. The animals were anesthetized with ether inhalation and the esophagus was exposed after removing the anterior wall of the thoracic cage, lungs, heart, and other mediastinal structures. The esophagus was tied at its lower end just above the diaphragm. A $1.5 \mathrm{~mm}$ outer diameter cannula was passed into the esophagus through the mouth of the rat, and a ligature was placed around the upper end of the esophagus with the cannula passing through it (Fig. 1). The thoracic cavity containing the esophagus was perfused with constantly circulating Ringer's solution at $37^{\circ} \mathrm{C} \pm 1$, which was oxygenated by bubbling through it a mixture of oxygen (95\%) and carbon dioxide (5\%). Intraluminal pressure was applied on the esophagus through the esophageal cannula by injecting fluid into it with a constant infusion pump (Harvard Apparatus Co., Inc., Millis, Mass., Model 944). The time between opening the animal and the conclusion of the test was 20 min or less for all the experiments. The pressures were measured with either a water manometer or a Sanborn pressure transducer (Model $267 \mathrm{BC}$ ) and recorded on a Sanborn recorder (Hewlett-Packard Co., Waltham, Mass.) The outer diameter was measured in the middle part of the esophagus with a measuring microscope (Model 15, Bausch \& Lomb Inc., Rochester, N. Y.) which was graduated in $1 / 20 \mathrm{~mm}$ intervals and produced a magnification of 20 . In some studies multiple photographs of the esophagus along with a measuring scale were taken, and the outer diameter of the esophagus was measured by projecting the slide and the scale reference on a large screen. This technique gave good agreement with the direct visual measurement of the outer diameter of the resting esophagus.

In the experiments described here, the outer diameter of the esophagus was measured. Estimates of the muscle thickness and the inner diameter of muscle layer, and the outer and inner diameters of the mucosal layer were ob- 
tained in six animals. After exposing the esophagus, we fixed it in formalin and made sections at three points at various levels. After staining the sections, we projected them on a screen, measured the inner and outer perimeters of the muscular and mucosal layers; from these findings calculated the diameters. The mean $( \pm \mathrm{SD})$ diameter was 1.62 $\pm 0.15 \mathrm{~mm}$, muscle layer thickness $0.22 \pm 0.02 \mathrm{~mm}$, and the inner diameter of the muscular layer was $1.17 \pm 0.26 \mathrm{~mm}$.

The mean outer diameter of the mucosal layer was larger than the inner diameter of the muscle layer in which it is contained, and for this reason, the mucosa in resting state was thrown into folds.

Change in the thickness of the muscle layer with the change in the outer diameter of the muscle wall can be calculated. If we assume that the volume and length, and thus also the cross-sectional area of the muscle coat and the mucosal layer remain unchanged, the thickness of the muscle coat will vary with the outer diameter as shown in Fig. 2. These calculations will hold provided the length of the esophagus does not change with increasing load and increasing diameter. This point was checked in another group of six rats. With stepwise increase of pressure to a maximum pressure of $80 \mathrm{~g} / \mathrm{cm}^{2}$ there was an $8 \%$ reduction in length. This change did not appreciably influence the calculated thickness of the wall and can therefore be ignored. The hypotheses that the cross-sectional area does not vary as the diameter changes and that shrinkage is caused by formalin fixation, were verified experimentally in six animals by introducing probes of fixed diameters in the lumen and measuring the corresponding outer diameters. From the diameters, the cross-sectional area was calculated and it was found that the area remains unchanged as the deformation proceeds but the formalin fixation causes a $47 \%$ shrinkage of the cross-sectional area.

The histologic examination shows that the muscle wall of the esophagus in the rat is composed of striated muscle

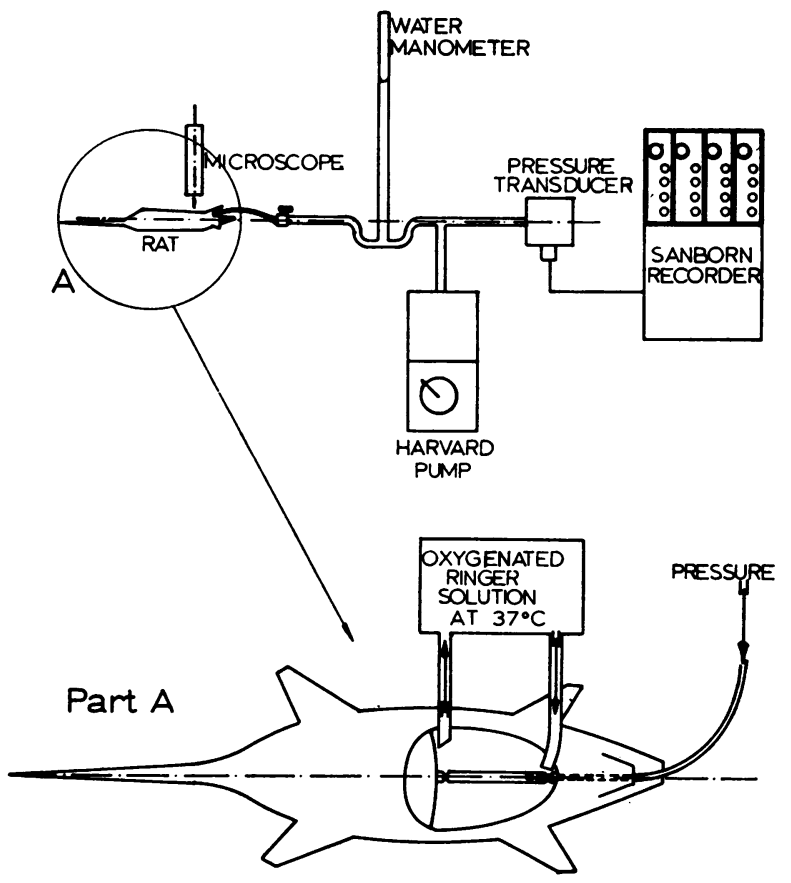

Figure 1 Experimental apparatus.

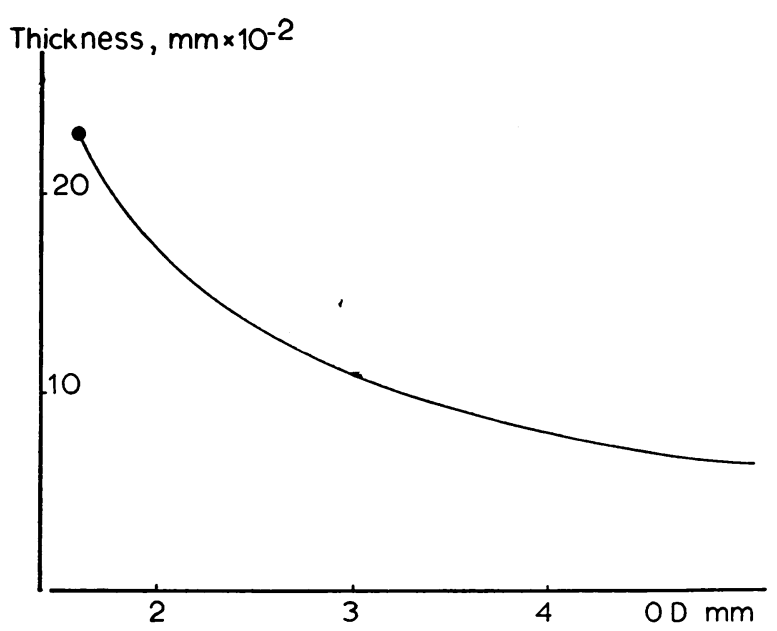

FIgURE 2 Thickness of muscle layer as a function of the outer diameter. The mean thickness of the muscle layer of the esophagus at resting diameter was estimated (point on the top of the curve) by making cross-sections of the organ in six animals and the curve was constructed by calculation assuming that the cross-sectional area of the muscle wall does not change during deformation.

fibers throughout the entire length of this organ. Internal to the muscle layer is the loose connective tissue of the submucosa, followed in order by the thin muscularis mucosa, the lamina propria, and the squamous epithelium.

The loose connective tissue between the mucosa and the muscle layer form a convenient line of cleavage so that the muscle layer can be separated from the mucosal layer and so that a "mucosal sac" without external muscle layer can be made. To do this, the outer part of the wall of the esophagus is gently held with fine forceps and by pulling on the forceps, the mucosal layer can be seen shining through the stretched muscle layer. A fine needle is then inserted between the mucosal sac and the muscle layer and some saline is injected so that the mucosa, along with a few fibers of muscularis mucosa are separated from the muscle layer. The muscle layer is then easily dissected from the mucosal sac, with care being taken to avoid injury to the sac. Histologic examination of these "mucosal sacs" shows complete absence of external muscle layer. The muscularis mucosa which is only a few fibers thick, remains attached to the outer wall of the "mucosal sac."

Viability studies. In our preparation, the blood supply to the esophagus was, of necessity, severed. The organ was kept viable by perfusing its outside with oxygenated Ringer at $37^{\circ} \mathrm{C}$. Such a technique is adequate only for thin-walled organs.

The viability of the preparation was tested; with a probe of $1.63 \mathrm{~mm}$ in diameter introduced into the esophagus, an electrical stimulus was applied with a square wave (voltage, $10 \mathrm{v}$; frequency, $30 / \mathrm{sec}$; duration, $1 \mathrm{msec}$ ). The esophageal muscle contracted to produce a mean pressure of $60 \pm 22$ $\mathrm{g} / \mathrm{cm}^{2}$.

After this, the esophagus was perfused with oxygenated Ringer as during the experiments and also an intraluminal load of $\mathrm{P}=80 \mathrm{~g} / \mathrm{cm}^{2}$ was applied for $15 \mathrm{~min}$. Electrical excitation of the esophagus at the end of this period generated a pressure of $P=62 \pm 25 \mathrm{~g} / \mathrm{cm}^{2}$. A further load was applied to the esophagus for another $15 \mathrm{~min}$. At the end of this 


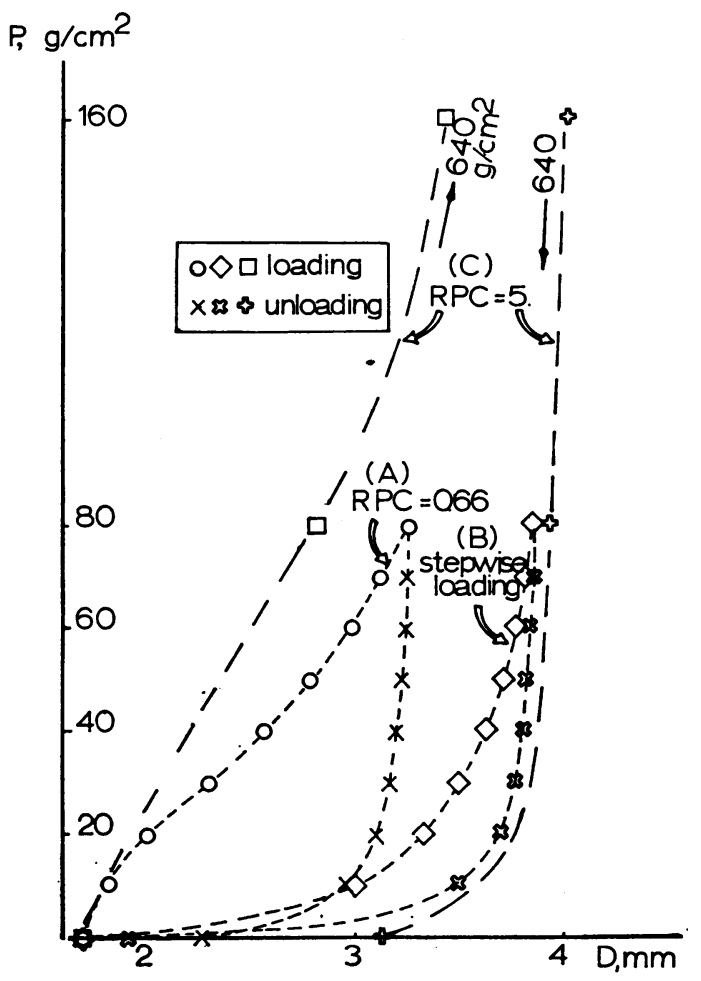

FIgURE 3 Mean loading and unloading curves for the esophagus at different rates of pressure change and at different maximum pressures. $(A) \mathrm{RPC}=0.66\left(\mathrm{~g} / \mathrm{cm}^{2}\right) / \mathrm{sec}$, $\mathrm{P}_{\max }=80 \mathrm{~g} / \mathrm{cm}^{2}$ (10 experiments); $(B)$ stepwise loading, $\mathrm{P}_{\max }=80 \mathrm{~g} / \mathrm{cm}^{2}$ (38 experiments); and (C) $\mathrm{RPC}=5$ $\left(\mathrm{g} / \mathrm{cm}^{2}\right) / \mathrm{sec}$ and $P_{\max }=640 \mathrm{~g} / \mathrm{cm}^{2}$ (10 experiments). Note the shift in the curves due to different rates of loading.

period the esophageal muscle produced a pressure of 58 $\pm 20 \mathrm{~g} / \mathrm{cm}^{2}$ on electrical stimulation. These studies indicate that the preparation retains excellent viability for over 30 min despite application of sustained load; all the experiments reported were completed within $20 \mathrm{~min}$. Christensen and Lund (12) have shown that isolated esophagus in vitro responds to distension as well as to electrical stimulation in a manner similar to that of the esophagus in intact animals. The viability of the mucosa was not separately tested, but because of the thin esophageal wall in rat we would assume that the mucosa also remained viable during the experiments.

\section{RESULTS}

Pressure diameter relationship. In a group of 38 animals, stepwise pressure changes were applied up to a maximum pressure $\left(P_{\max }\right)=80 \mathrm{~g} / \mathrm{cm}^{2}$. Small pressure changes were applied at low pressures and large ones at higher pressures. After each pressure increment the diameter rapidly increased, and then the deformation apparently stopped. When the deformation had subsided, a new pressure increment was applied. A similar procedure was followed during unloading. The curves ob- tained showed a nonlinear pressure diameter relationship, the compliance descreasing with increasing loads.

Rate of pressure change and the pressure diameter relationship. When small increments of pressure at a constant rate of pressure change $(\mathrm{RPC})^{\mathrm{1}}=0.66\left(\mathrm{~g} / \mathrm{cm}^{2}\right) /$ sec were applied up to $80 \mathrm{~g} / \mathrm{cm}^{2}$, the loading curve was quite different and was sigmoid in shape. The compliance increases at first and then starts to decrease as the pressure increases over $40 \mathrm{~g} / \mathrm{cm}^{2}$ (Fig. 3). This sigmoid behavior is entirely due to the muscle layer. At small diameters the mucosa gives no contribution as it is thrown into longitudinal folds.

The loading curves showed a shift to the right with decreasing rates of pressure increase so that the curve for stepwise loading was to the extreme right (Fig. 3). This appears mostly to be due to time-related deformation, or creep, occurring in the muscle wall at slow rates of loading.

The unloading curves in all these experiments were qualitatively similar to each other. They were exponential in character and exhibited no sigmoid behavior. All the unloading curves were different from the loading curves (Fig. 3).

Comparison of the pressure-diameter curves for mucosa alone and the esophagus. Loading and unloading were applied on the mucosal sac, with muscle removed, at a steady $\mathrm{RPC}=0.66\left(\mathrm{~g} / \mathrm{cm}^{2}\right) / \mathrm{sec}$. The behavior of the mucosa was very different from that of the esophagus at the same RPC, but was remarkably similar to that of the esophagus under stepwise loading (Fig. 4); the

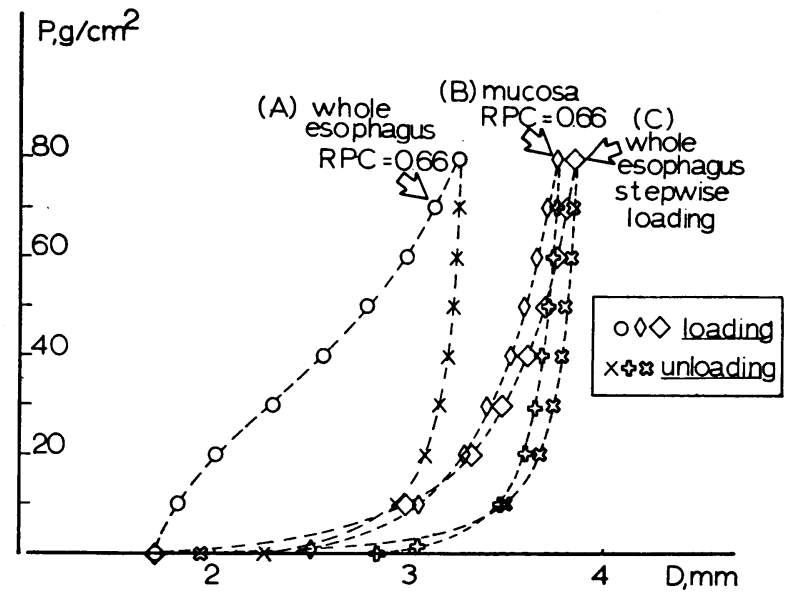

FIgUre 4 Mean loading and unloading curves for the esophagus at $\mathrm{RPC}=0.66\left(\mathrm{~g} / \mathrm{cm}^{2}\right) / \mathrm{sec}(A)$; for the mucosa at $\mathrm{RPC}=0.66\left(\mathrm{~g} / \mathrm{cm}^{2}\right) / \mathrm{sec}(B)$; and for the whole esophagus with stepwise loading $(C)$. The behavior of the esophagus at $\mathrm{RPC}=0.66\left(\mathrm{~g} / \mathrm{cm}^{2}\right) / \mathrm{sec}$ is different from the behavior with stepwise loading. The curves of the esophagus with stepwise loading are, however, very similar to those of the mucosa at $\mathrm{RPC}=\left(\mathrm{g} / \mathrm{cm}^{2}\right) / \mathrm{sec}$. (Each point is a mean of 10 experiments.) 
only difference was noticed at low loads, when the mucosa undergoes a large deformation before starting to bear a load.

Rate-dependent deformation. The dependence of the diameter on the pressure and rate of pressure increase $(\mathrm{RPI})^{1}$ is shown in Fig. 5. In this figure the diameter during the loading portions in the preceding experiments has been plotted for various pressures and two rates of pressure increase. The curves of constant pressure show that for the same pressure the diameter increases with decreasing RPI and that the increase is more marked for a very low RPI.

Dependence on the history of loading. To find the effect of the previous loading history on the pressurediameter relationship each esophagus was loaded and unloaded several times consecutively. In one experiment ten different specimens were loaded five times by varying the pressure between 0 and $640 \mathrm{~g} / \mathrm{cm}^{2}$ at a constant $\mathrm{RPC}=5 \quad\left(\mathrm{~g} / \mathrm{cm}^{2}\right) / \mathrm{sec}$. With each loading-unloading cycle the loading curves moved to the right (Fig. $6 \mathrm{~A}$ ), showing an increase in diameter. The increase was more marked at lower loads and in the initial cycles. The shift in the loading curve was most prominent between the first and second cycle. The shift decreased progressively as more cycles occurred. A similar but much smaller shift was shown by the unloading curves (Fig. $6 \mathrm{~B})$. A sigmoid behavior was found in the first two cycles for $\mathrm{RPC}=0.66\left(\mathrm{~g} / \mathrm{cm}^{2}\right) / \mathrm{sec}, P_{\max }=80 \mathrm{~g} / \mathrm{cm}^{2}$. After the first two cycles the sigmoid portion disappeared (Fig. 7).

The mucosa alone showed a nonsigmoid behavior $\left(R P C=0.66, P_{\max }=80 \mathrm{~g} / \mathrm{cm}^{2}\right.$ ) except that the paths for loading and unloading remained completely unchanged after the second cycle (Fig. 8).

The area of hysteresis loop. The area of the hysteresis loop is the area enclosed by a loading and the corresponding unloading curve. The area of the hysteresis loop was different in the first cycles for different maximal loads and different rates of pressure change. The area was smaller for stepwise loading than for a steady $\mathrm{RPC}=0.66\left(\mathrm{~g} / \mathrm{cm}^{2}\right) / \mathrm{sec}$. Thus, the hysteresis loop is bigger for faster rates of pressure change and is reduced as the RPC decreases, and some time is available for the the deformation to take place. The loop was also bigger for the whole esophagus than that for the mucosa alone, suggesting that it is the muscular layer which contributes most significantly to the area of the hysteresis loop (Fig. 4). On repeating loading-unloading cycles the shift of the loading curves is bigger than the shift of the unloading curves, which is always very small. As a

\footnotetext{
${ }^{1}$ Abbreviations used in this paper: $\mathrm{K}$, Fung's modulus; $\mathrm{L}_{1}$, minimum length; $L_{2}$, maximum length; $L_{0}$, a length comprised between $\mathrm{L}_{1}$ and $\mathrm{L}_{2} ; \mathrm{RPC}$, constant rate of pressure; $\mathrm{RPI}$, rate of pressure increase.
}

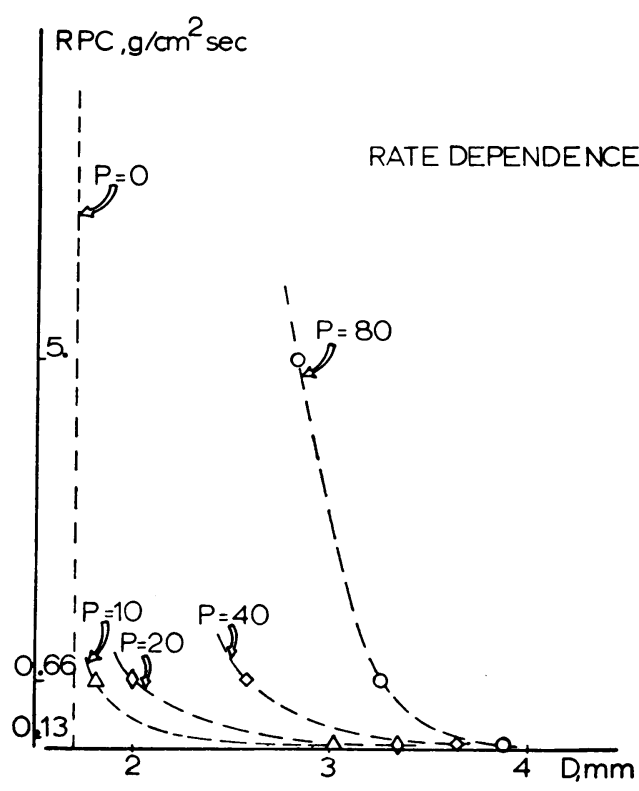

Figure 5 Influence of the rate of pressure change on the diameter of the esophagus at a given pressure. Mean curves giving the dependence of the diameter on the RPC at various constant pressures $\left(10-20-40-80 \mathrm{~g} / \mathrm{cm}^{2}\right)$ have been constructed by plotting points from the loading curves of the esophagus at $\mathrm{RPC}=5\left(\mathrm{~g} / \mathrm{cm}^{2}\right) \mathrm{sec},(10$ experiments $)$, $\mathrm{RPC}=0.66\left(\mathrm{~g} / \mathrm{cm}^{2}\right) / \mathrm{sec}\left(10^{\circ}\right.$ experiments $)$, and stepwise loading (38 experiments). The average RPC for stepwise loading was $0.13\left(\mathrm{~g} / \mathrm{cm}^{2}\right) / \mathrm{sec}$. At smaller RPC, the curves of constant pressure are not as steep as at a larger RPC. This indicates that the diameter of the esophagus at a given pressure and at smaller RPC is very readily influenced by small changes in the RPC.

consequence the area of the hysteresis loop progressively decreases in all experimental situations, and eventually becomes constant as a stable hysteresis loop (2) is reached and successive loading-unloading cycles follow the same path.

The number of cycles required to reach a stable hysteresis loop varies with the type of material, the RPC, and the maximum load reached. Thus for the mucosa $\left(\mathrm{P}_{\max }\right.$ $\left.=80 \mathrm{~g} / \mathrm{cm}^{2}, R P C=0.66\left(\mathrm{~g} / \mathrm{cm}^{2}\right) / \mathrm{sec}\right)$, the stable hysteresis loop is reached in the second cycle and the third loading-unloading cycle is just superimposed on the second one. On the other hand, for the esophagus at the same $P_{\max }$ and RPC, the stable loop is not reached even after six cycles.

Residual deformation. The outer diameter of the esophagus at the end of a loading and unloading cycle was different from the initial diameter at the onset of the cycle. The change in diameter of the esophagus from its initial diameter, after it has undergone a loading cycle, is the residual deformation. Like the area of the hysteresis loop, the residual deformation was dependent upon the rate of pressure change, maximum pressure 

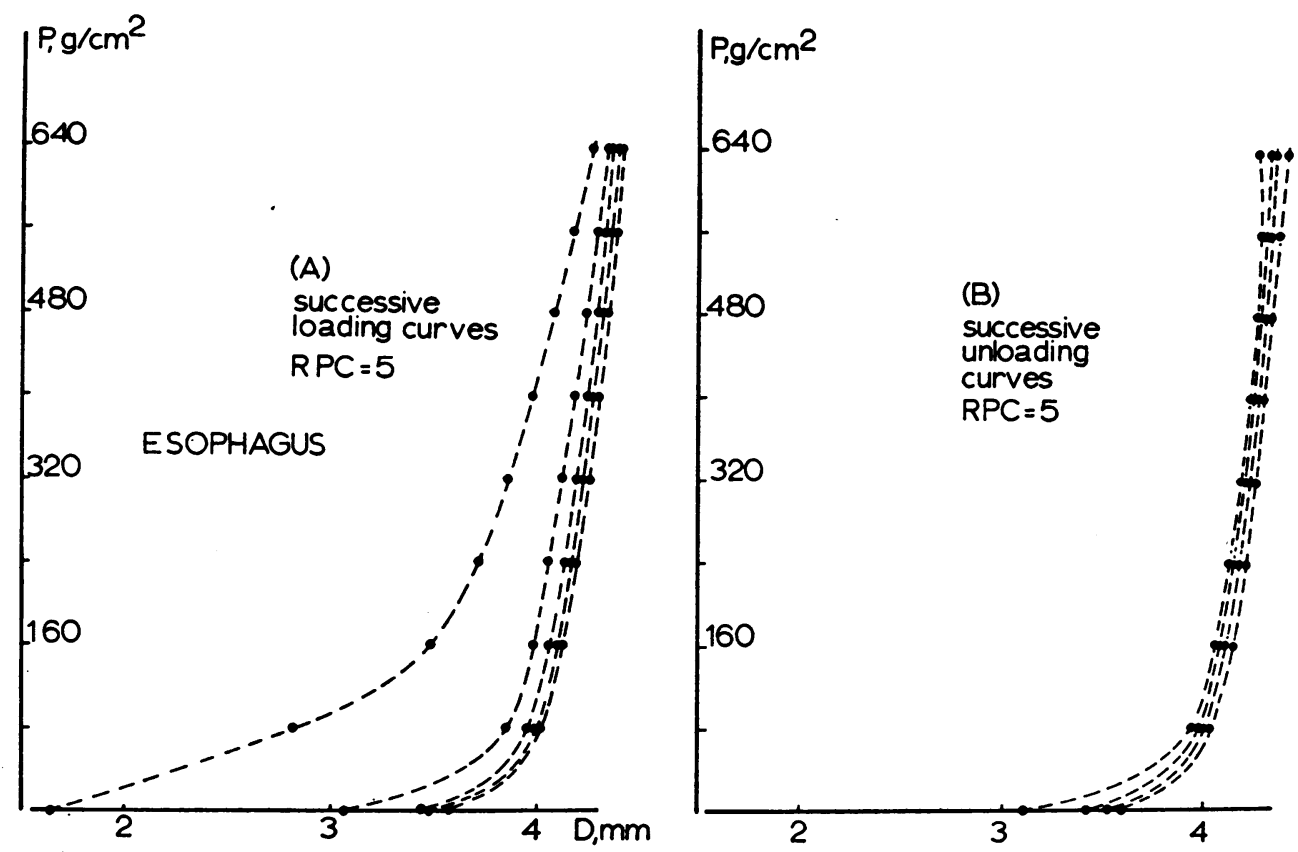

FIgURE 6 Successive loading $(A)$ and unloading $(B)$ curves for the esophagus at $\mathrm{RPC}=5$ $\left(\mathrm{g} / \mathrm{cm}^{2}\right) / \mathrm{sec}, \mathrm{P}_{\max }=640$. (Mean of 10 experiments.) With each new cycle loading curves shift to the right, producing an increase in diameter. The shift is larger at low pressure, and for the first cycle. The unloading curves also show a similar shift to the right but the shift with successive cycles is much smaller.

reached, the type of the material, and the number of cycles applied. When adaptation has occurred with the hysteresis loop the residual diameter also becomes fixed. The amount of change in diameter between two successive cycles becomes progressively smaller until it

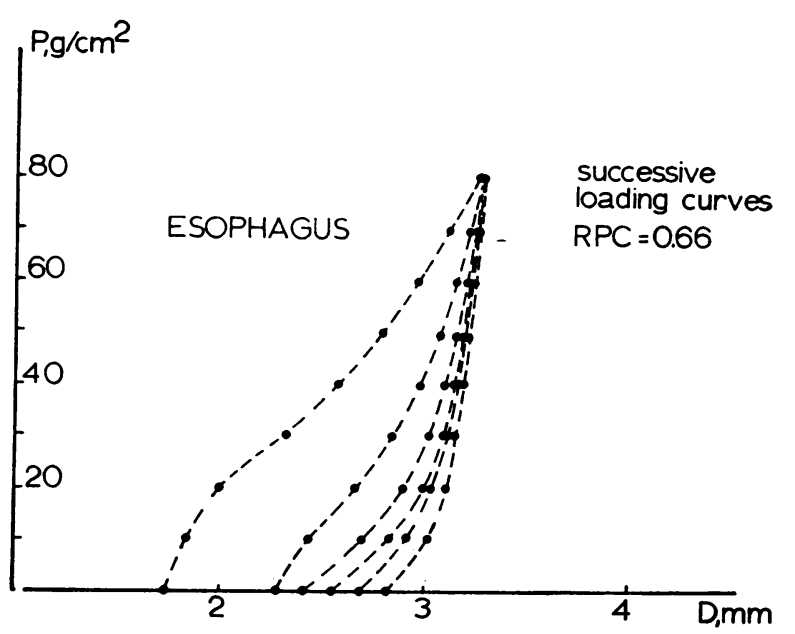

Figure 7 Successive loading curves of the esophagus at $\mathrm{RPC}=0.66\left(\mathrm{~g} / \mathrm{cm}^{2}\right) / \mathrm{sec}, \mathrm{P}_{\max }=80 \mathrm{~g} / \mathrm{cm}^{2}$. (Mean of 10 experiments.) Note that the sigmoid behavior in the first two cycles disappears on subsequent four cycles. With each new cycle the curve shifts to the right. disappears (Fig. 9). The total residual deformation, which is the sum of the residual deformations occurring in each cycle, increases sharply at first, then slowly, and finally becomes fixed, as the stable residual deformation. The stable residual deformation was reached after two cycles for the mucosa $\left(\mathrm{RPC}=0.66\left(\mathrm{~g} / \mathrm{cm}^{2}\right) /\right.$ sec, $P_{\max }=80 \mathrm{~g} / \mathrm{cm}^{2}$ ) but was not reached for the esophagus at the same $\mathrm{RPC}$ and $\mathrm{P}_{\max }$. At $\mathrm{RPC}=5$ $\left(\mathrm{g} / \mathrm{cm}^{2}\right) / \mathrm{sec}$ and $P_{\max }=640 \mathrm{~g} / \mathrm{cm}^{2}$, the stable residual deformation was almost reached after five cycles.

The residual change in the diameter of the esophagus after just one cycle was influenced by the rate of pressure change and the maximum pressure reached. The residual deformation was most marked for $\mathrm{P}_{\max }=640$ $\mathrm{g} / \mathrm{cm}^{2}$ and $\mathrm{RPC}=5\left(\mathrm{~g} / \mathrm{cm}^{2}\right) / \mathrm{sec}$, least for the stepwise loading, and intermediate for $P_{\max }=80 \mathrm{~g} / \mathrm{cm}^{2}$ and $\mathrm{RPC}=0.66\left(\mathrm{~g} / \mathrm{cm}^{2}\right) / \mathrm{sec}$. The residual deformation for mucosa alone was smaller than for the whole esophagus at comparable RPC and $\mathrm{P}_{\max }$.

Time-dependent deformation (creep). The influence of creep was studied in 10 rats. A pressure of $80 \mathrm{~g} / \mathrm{cm}^{2}$ was suddenly applied and kept for $15 \mathrm{~min}$. The diameter was measured before application of the load and again every minute thereafter. The diameter without load was $1.73 \mathrm{~mm}$ ( $\mathrm{sD} \pm 0.15)$. There was a large increase in diameter in the 1st min of application of the load and after $1 \mathrm{~min}$, the diameter was $3.71 \mathrm{~mm}$ ( $\mathrm{SD} \pm 0.27$ ). Af- 
ter $15 \mathrm{~min}$ the diameter was $3.84 \mathrm{~mm}$ ( $\mathrm{SD} \pm 0.27$ ) (Fig. 10). This indicates that most of the deformation occurs during the 1st min after application of the load.

Three possible factors could influence this: $(a)$ relaxation in the muscle, $(b)$ progressive realignment of the collagen fibers and microfibrils present (13), with resulting viscous resistance by the ground substance; and (c) relaxation inside the microfibrils themselves (8).

For primary tendon bundles in which the collagen fibrils are aligned in a very orderly fashion, it has been found (8) that creep is small. This leads us to believe that the larger part of the deformation which happens in the 1st min might be due to muscle relaxation as well as to realignment and reorientation of collagen fibers.

Failure strength of the esophagus and of the mucosa. The contribution of the mucosa to the failure strength of the esophagus was estimated by comparing the failure pressure of the esophagus with that of the mucosa alone. To test the mucosa alone the muscular layer was carefully dissected away in five rats and the mucosa was left in place. A rate of pressure increase (RPI) of 200 $\left(\mathrm{g} / \mathrm{cm}^{2}\right) / \mathrm{sec}$ was applied. At this rate the failure pressure for the intact esophagus was $1190 \mathrm{~g} / \mathrm{cm}^{2}$ (SD \pm 78 ) and the mean failure diameter was $5.08 \mathrm{~mm}$ ( $\mathrm{SD} \pm 0.14$ ). At the same RPI, the mean ( $\pm \mathrm{SD}$ ) failure pressure and failure diameter for the mucosa alone were $694( \pm 53)$ $\mathrm{g} / \mathrm{cm}^{2}$ and $4.69( \pm 0.19) \mathrm{mm}$ respectively.

The failure pressure of the mucosa alone was $55 \%$ of the whole esophagus at the same RPI. However, as the failure pressure of muscle layer could not be separately tested with our technique, the precise contribution of the mucosa to the failure pressure of the whole esophagus cannot be defined with certainty.

Failure strength and rate of loading. The dependence of the failure pressure and failure diameter of the

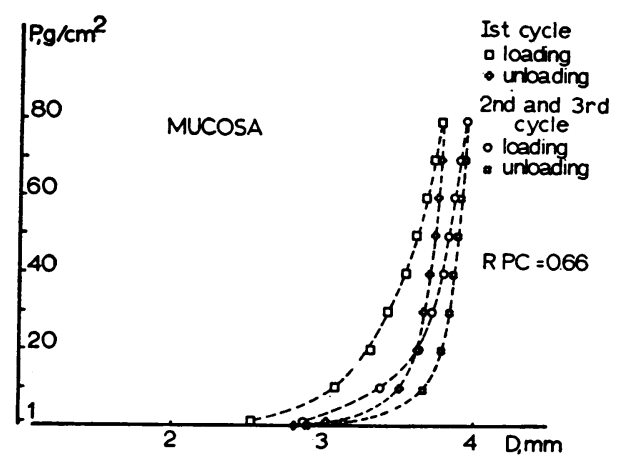

FIGURE 8 Successive loading-unloading cycles for the mucosa at $R P C=0.66\left(\mathrm{~g} / \mathrm{cm}^{2}\right) / \mathrm{sec}$, and $P_{\max }=80 \mathrm{~g} / \mathrm{cm}^{2}$. (Mean of 10 experiments.) The curves in the second cycle are different from those in the first cycle. The third cycle has the same curves as the second, indicating that a stable hysteresis loop has been reached.

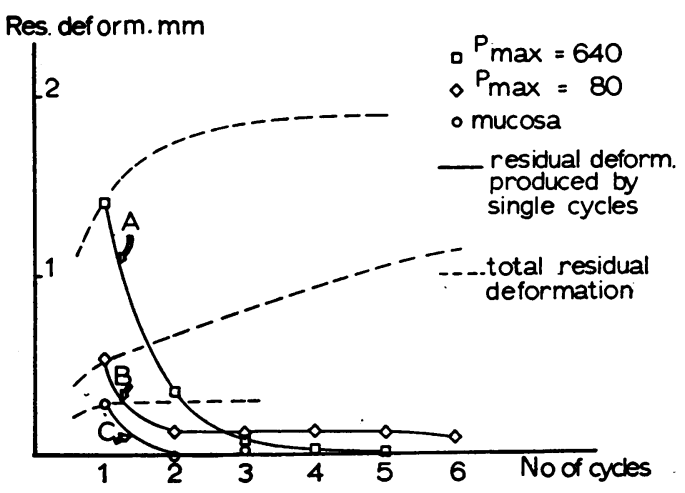

FIGURE 9 Factors influencing the residual and total deformation. The residual deformation of the esophagus is larger at $\mathrm{RPC}=5\left(\mathrm{~g} / \mathrm{cm}^{2}\right) / \mathrm{sec}$ and $\mathrm{P}_{\max }=640 \mathrm{~g} / \mathrm{cm}^{2}(A)$ than at $\mathrm{RPC}=0.66\left(\mathrm{~g} / \mathrm{cm}^{2}\right) / \mathrm{sec}$ and $P_{\max }=80 \mathrm{~g} / \mathrm{cm}^{2}(B)$. The mucosa $(C)$, when compared to the whole esophagus at the same $R P C=0.66\left(\mathrm{~g} / \mathrm{cm}^{2}\right) / \mathrm{sec}$ and $P_{\max }=80 \mathrm{~g} / \mathrm{cm}^{2}$, shows less residual deformation. With each successive cycle the residual deformation (i.e. the difference in diameter at the end of two successive cycles) progressively decreases for all the experiments till it tends to reach zero. Stable residual deformation (zero level) is reached very soon (third cycle) for the mucosa. For the esophagus, five cycles are required at $\mathrm{RPC}=5\left(\mathrm{~g} / \mathrm{cm}^{2}\right) / \mathrm{sec}$ and $\mathrm{P}_{\max }=640\left(\mathrm{~g} / \mathrm{cm}^{2}\right)$ $(A)$ and more than six at $\mathrm{RPC}=0.66\left(\mathrm{~g} / \mathrm{cm}^{2}\right) / \mathrm{sec}$ and $\mathrm{P}_{\max }=80\left(\mathrm{~g} / \mathrm{cm}^{2}\right)(B)$. (Each point represents mean of several experiments.)

esophagus on the rate of loading was tested by comparing the failure pressure and diameter of the intact esophagus at different rates of pressure increases. Five specimens were tested at $\mathrm{RPI}=200\left(\mathrm{~g} / \mathrm{cm}^{2}\right) / \mathrm{sec}$., and five at $R P I=5\left(\mathrm{~g} / \mathrm{cm}^{2}\right) / \mathrm{sec}$.

The failure pressure was markedly influenced by the rate of pressure increase, being significantly lower for

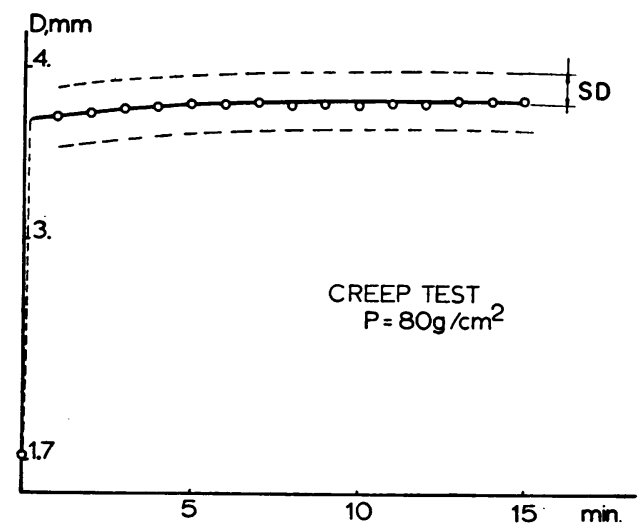

FIgURE 10 Time dependent deformation. After measuring the resting diameter of the esophagus, a pressure of 80 $\left(\mathrm{g} / \mathrm{cm}^{2}\right)$ was suddenly applied. The diameter more than doubled in the first minute and then only a small change occurred in the next $14 \mathrm{~min}$. Each dot represents the mean of 10 experiments. 


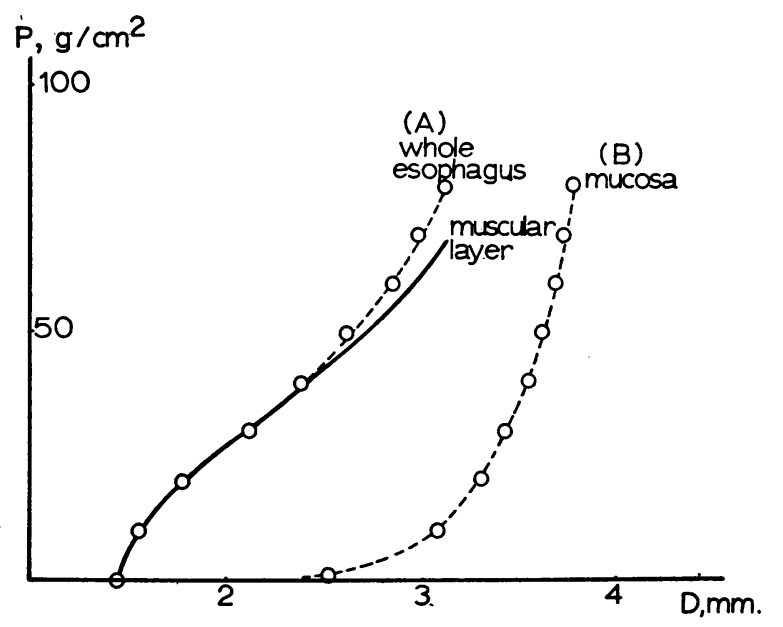

FIGURE 11 Contribution of muscular and mucosal layers to the strength of the esophagus at low pressures. The pressure-diameter curve for the muscle layer has been calculated by taking the difference between the mean curves for the esophagus (as a function of the inner diameter of this muscle layer which is given by Inner diameter = Outer diameter $-2 \times$ thickness) and the mucosa alone (as a function of outer diameter of the mucosa, which would be equal to the inner diameter of the muscle layer when the mucosa is fully distended). For pressures less than $40 \mathrm{~g} / \mathrm{cm}^{2}$ the contribution of the mucosa is less than $1 \mathrm{~g} / \mathrm{cm}^{2}$.

an RPI of $5\left(\mathrm{~g} / \mathrm{cm}^{2}\right) / \mathrm{sec}\left(\mathrm{P}=864 \pm 131 \mathrm{~g} / \mathrm{cm}^{2}\right)$, than for $R P I=200\left(\mathrm{~g} / \mathrm{cm}^{2}\right) / \mathrm{sec} \quad\left(P=1190 \pm 78 \mathrm{~g} / \mathrm{cm}^{2}\right)$. The change in failure pressure is not surprising. By reducing the RPI the contribution of the viscous element is reduced. At RPI $=200\left(\mathrm{~g} / \mathrm{cm}^{2}\right) / \mathrm{sec}$ the failure is reached in $6 \mathrm{sec}$, while at $R P I=5\left(\mathrm{~g} / \mathrm{cm}^{2}\right) / \mathrm{sec}$ it takes $172 \mathrm{sec}$. In this longer time some stress relaxation takes place, thus reducing the final failure pressure.

The failure diameter was also influenced by the RPI but the failure diameter was larger for higher RPI. The failure diameter was $4.77( \pm 0.30) \mathrm{mm}$ for RPI = $5\left(\mathrm{~g} / \mathrm{cm}^{2}\right) / \mathrm{sec}$, and $5.08( \pm 0.14) \mathrm{mm}$ for $\mathrm{RPI}=200$ $\left(\mathrm{g} / \mathrm{cm}^{2}\right) / \mathrm{sec}$.

\section{DISCUSSION}

The esophagus in experimental animals or in man is designed to perform two basic functions; namely, "holding" and "propelling." With respect to the first function, the esophagus behaves like an inert pipe, the purpose of which is to contain materials as they travel through it either from the mouth to the stomach, as during swallowing, or backwards, as during vomiting. The propelling force in the esophagus is provided by a wavelike muscular contraction or peristalsis. The chief concern of this investigation was to study the "holding" function of this organ and to evaluate its response to various types of intraluminal pressures.
In general, the pressure diameter relationship of the esophagus was exponential. This behavior is, obviously, due to both the mucosa and the muscle coat which in turn depends on the behavior of individual components like the epithelial cells, the connective tissue, and the muscle fibers and their interaction with each other.

The structural organization of the esophageal wall contributes to nonlinear stress-strain relationship. With small deformation the mucosa does not contribute to the strength of the wall, but it just unfolds or takes very little load until the outer mucosal diameter reaches $2.40 \mathrm{~mm}$, which corresponds to an outer esophageal diameter $2.65 \mathrm{~mm}$ (Fig. 11). This finding has some significance. It shows that mucosal disease by itself does not influence the diameter of the esophagus at small loads such as might be imposed by a bolus of food. However, with muscle involvement, as in scleroderma, significant changes in the diameter of the esophagus may occur.

Data on the stress-strain relationship of epithelial cells are scanty, but nonlinear stress-strain relationship has been shown to exist for connective tissues and the muscle fibers. In the collagen tissue, such a relationship has been attributed to a recruitment model $(8,9,13)$ which can be explained in the following way: collagen fibers in the unstretched state form wavy patterns and are more or less disorganized in orientation, depending on the function of the organ in which they are located. With increasing deformation an increasing number of fibers straighten and start bearing load $(8,9)$. Moreover, with increasing loads, realignment may occur within the single collagen fibers, as the microfibrils straighten and realign in their turn. Other fibers, like elastic and reticular, also become reoriented with increasing loads.

Thus the stiffness of connective tissues increases with the load, producing an exponential stress-strain relationship. Interestingly, however, the exponential stressstrain relationship appears not only for composite connective tissues, where architectural rearrangements contribute to it, but also for the single fibrils. Tests run on single elastic fibrils (14) show that a single fibril, teased out of the bundle which contains it, still shows increasing stiffness with increasing load.

Nonexcited muscles also behave in a similar way. The stress-strain relationship of "passive" muscles is exponential in character $(5,6)$, which could probably be explained by the presence of connective tissue sheaths around the muscle fibers.

Hill (15) reported that for relaxed muscles the logarithm of the tension was proportional to the length of the stretched muscle. In 1967, Fung (16) found this also to be true for the mesenteric membrane of the rabbit. In 1969, Stromberg and Wiederhielm (8) found 
that rat tendons and other connective tissues have the same property.

In mathematical terms this property can be described by

$$
\frac{\mathrm{dT}}{\mathrm{dE}}=K \mathrm{~T}
$$

where stress

$$
T=\frac{P \times D_{0}}{2 t_{0}}
$$

and strain

$$
E=\frac{1}{2}\left(\frac{D}{D_{0}}\right)^{2}-1
$$

and

$$
\begin{aligned}
P & =\text { intraluminal pressure } \\
D_{0} & =\text { initial diameter } D \\
t_{0} & =\text { initial thickness }
\end{aligned}
$$

This equation is satisfied by

$$
\mathrm{T}=G \mathrm{e}^{K \mathbf{E}}
$$

In this equation, however, when $\mathrm{E}=0, \mathrm{~T} \neq 0$, but at zero strain the stress should also be zero.

In order to have $T=0$ at $E=0$, we will modify equation (1) and write

$$
\frac{\mathrm{dT}}{\mathrm{dE}}=K \mathrm{~T}+\mathrm{H}
$$

which is satisfied by

$$
\mathrm{T}=G \mathrm{e}^{K \mathrm{E}}-\mathrm{G}
$$

where $H=K G$ is the slope of the curve at $E=0$.
Thus the one-dimensional stress-strain relationship of many soft biological tissues, if the hysteresis loop is neglected, is described to some approximation by two constants, $K$ and $G$.

Stromberg and Wiederhielm (8) showed that $K$ (Fung's modulus) decreases with decreasing degrees of organization of the tissues. The constant $K$ is 450 for primary tendon bundles in rat and is 12 for rabbit mesentery. Mesentery is a typical example of loose connective tissue constituted by a randomly oriented, twodimensional network, while primary tendon bundles are highly organized. In the rat's esophagus $K=2.3, G=$ 5 for the whole esophagus under stepwise loading, and $K=3.6, G=0.0052$ for the mucosa alone under constant RPI. In general $G$ is very small for tissues that undergo a large deformation before a small increase in stress appears, as is the case of the mucosa. The calculated stress-strain curves for the esophagus and mucosa are very close to the curves obtained experimentally during loading (Fig. 12, A, B), and thus would give an accurate representation of the behavior of the esophagus if it were perfectly elastic. However, the loading curves of the esophagus and the mucosa alone, are different from the unloading curves in all experiments. The unloading curve is always to the right of the loading curve, forming a loop (hysteresis loop). The area of the hysteresis loop, which is enclosed by a loading and the successive unloading curve, is directly proportional to the work dissipated in the loading-unloading cycle. The area of the hysteresis loop depends on the history of
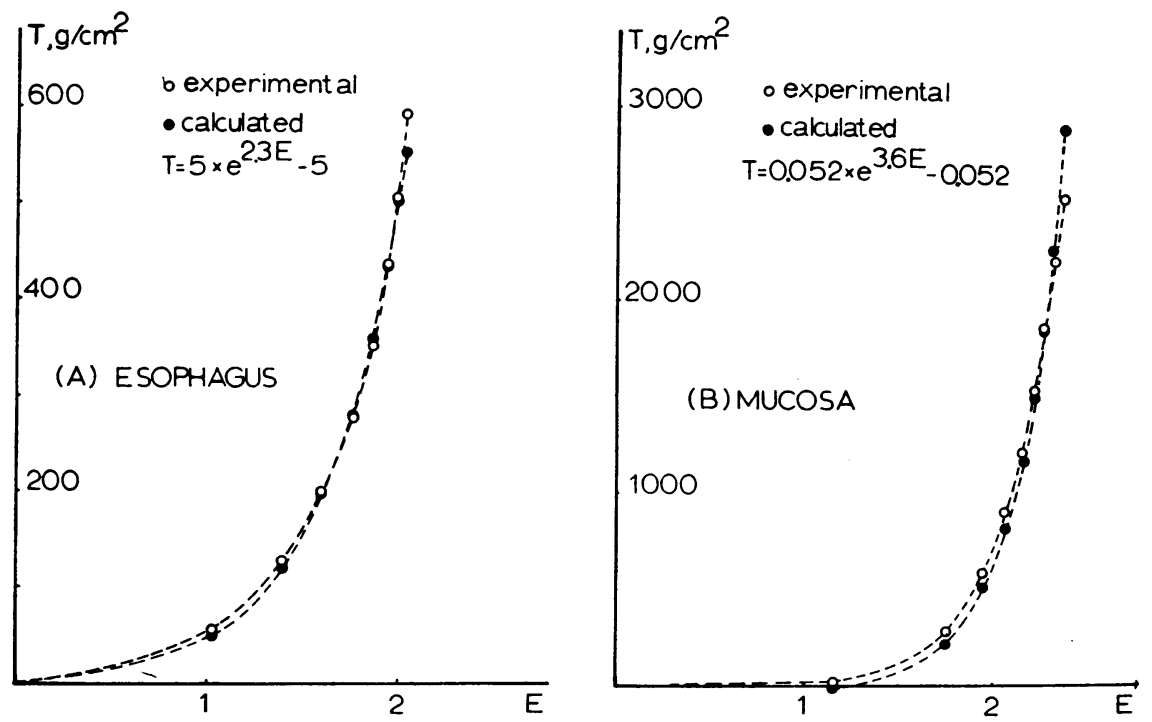

FIgURE 12 Comparison of the experimentally determined stress-strain relationship with the values calculated from the equation. $\mathrm{T}=G \times \mathrm{e}^{\mathrm{KE}}-G$ For the Esophagus under Stepwise Loading. For the whole esophagus $G=5 ; K=2.3$ and for the mucosa $G=0.052 ; K=3.6$. Note the close agreement between the experimental and the calculated curves. The experimental curves are mean of 10 experiments. 
loading. This dependence is different for the esophagus and for the mucosa alone.

For the mucosa, at $\mathrm{RPC}=0.66\left(\mathrm{~g} / \mathrm{cm}^{2}\right) / \mathrm{sec}$ and $P_{\max }=80 \mathrm{~g} / \mathrm{cm}^{2}$, the hysteresis loop after the second cycle repeats the same paths (stable hysteresis loop). Whereas, for the whole esophagus, the stable hysteresis loop is not reached before six or more loading and unloading cycles. The reduction in the hysteresis loop from one cycle to another is mainly due to the change of the loading curve, while the unloading curve shows only little change. The appearance of the stable hysteresis loop was first described by Remington in 1955 (2) and has been called adaptation by some (4).

The shift between the first and second hysteresis loop is probably due to deformations and rearrangements occurring during the first cycle, and depends on the maximum load applied. The stable hysteresis loop appears to be due to energy dissipated during loading and unloading, as the connective tissue fibers change their orientation within the viscous ground substance. When the fibers are all parallel, as in tendons, the stable hysteresis loop is very small.

Fukaya, Martin, Young, and Katsura (4) observed that changing to higher tension requires new adaptation. They thought that the rearrangement which resulted in repeated pathways for a given maximum load is disturbed when the maximum load is increased. and repeated cycling is necessary to establish a new rearrangement compatible with the new peak load.

The difference in behavior between the whole esophagus and the mucosa alone can be attributed to the presence of the muscular layer (muscularis externa). The loading curves for the muscular layer are not exponential, but exhibit sigmoid behavior in the first two cycles. After the first two cycles the sigmoid behavior disappears and the curves become exponential in shape. The reason for such behavior is not entirely clear. Tetanized muscles (muscles under sustained state of contraction) have been shown (6) to exhibit sigmoid stress-strain relationship, the sigmoid bump being related to the contractile activity of the muscle. The sigmoid curve is also given by the superimposition of the curve of "active" tension, and the curve of "passive" tension. The curve of "passive" tension, that is, the stress-strain curve of a "passive" muscle, is exponential in shape. Muscular fibers can exert active tension until they have been shortened to a minimum length, $L$. When such a minimum length is reached, the muscle cannot contract any further and the active tension decreases to zero. Also muscular fibers lose their ability to contract if they are stretched above a certain maximum length, L2. For some length, Lo (comprised between $\mathrm{L}_{1}$ and $\mathrm{L}_{2}$ ) the muscles can exert their maximum active tension $(5,6)$. These observations suggest the presence of a phenomenon similar to what has been described as Starling's law of the heart (17).

The superposition of the exponential "passive" curve and of the parabolic "active" curve gives a sigmoid curve of total tension for muscular fibers which is similar to that found for loading in the first cycle. It is possible that the sigmoid behavior may be due to the muscles maintaining themselves in a state of partial contraction or tone. However, the fact that the sigmoid pattern gives way to an exponential pressure-diameter relationship with repeated cycles suggests that the "active tone" of the muscle is not continuously present and repeatedly exhibited. This would explain the presence of sigmoid stress-strain relationship of the muscle in the first cycle and its disappearance in subsequent ones.

When pressure is applied, the contraction is gradually destroyed by viscous deformation as the test goes on. Thus at low tension the muscles act like inert viscous elements. This explains why the behavior of the mucosa with a constant RPC is so similar to that of the esophagus under stepwise loading (Fig. 4). The stepwise loading, where a certain time passes between successive increases in load, gives the muscles time to relax $(18,19)$, until their contribution disappears, and the entire esophagus behaves like the mucosa.

In most experiments described in literature $(2-9,14$, $16,18-21)$, tissues were removed from the body and mounted on a testing device. Although the effect of cutting an artery on its elasticity is small (22), many biological tissues are very soft and undergo large deformations when comparatively small forces are applied. For this reason it is difficult to measure the resting or undisturbed dimensions after the tissues are removed from the body. Moreover, the mechanical properties of biological tissues depend on the history of loading. If some biological tissues are stretched and then released, their behavior upon successive stretching will be affected by the rate of application and the magnitude of the previous load. Thus the effect of removing the tissues from the body and of installing them in the testing device becomes hard to estimate and eliminate since it is very easy to produce large deformations during these processes. For these reasons, we feel that the in situ technique is desirable in the investigation of mechanical behavior of biological tissues.

The results of the experiments on the failure pressure indicate that the mucosa may make important contributions to the strength of the esophageal wall at the failure pressure. This is consistent with the observation that the mucosal inflammation is an important factor in the production of esophageal rupture (23). 


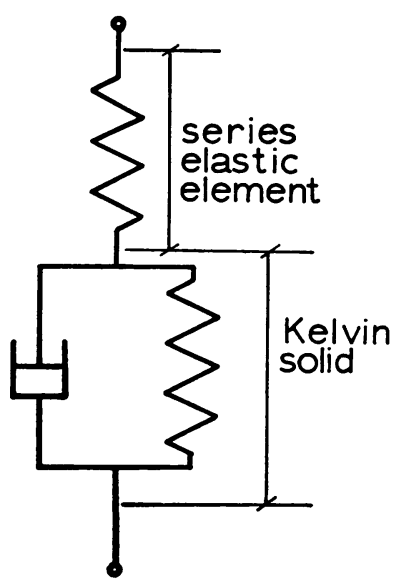

FIGURE 13 Three parameter solid.

These studies further show that the failure pressure is influenced by not only the maximum pressure reached but also the rate of pressure increase. Moreover, the diameter at which rupture occurs is also modified by the rate of pressure increase. The failure diameter is larger with a higher RPI. This phenomenon can be explained by a model of spring and dashpot (Fig. 13). If a viscoelastic element (Kelvin solid) is in series with an elastic element $(20,21)$, one could say that at higher pressures associated with larger RPI, the series elastic element deforms more than the viscoelastic element. If the increase of deformation of the series elastic element is larger, because of higher load, than the decrease in deformation of the viscous element due to higher rate, then the breaking diameter would be larger at a larger RPI.

In conclusion, this study describes a technique for investigation of the mechanical properties of the esophagus in situ, which is desirable because the mechanical behavior is modified by inadvertent load applications when in vitro studies are performed. Because the overall organization of the walls of various segments of gastrointestinal tract is closely similar, it appears that they will show similar qualitative responses. A simple equation has been given for representation of the elastic behavior of this material. The data provide some experimental background for constructing constitutive equations for the walls of the gastrointestinal tract.

\section{ACKNOWLEDGMENTS}

The authors wish to thank Dr. Paul Schwartz for his helpful suggestions.

This research was supported in part by the Rose Brothers Fund at Yale University, and in part by the American $\mathrm{Ma}$ chine and Foundry Foundation.

\section{REFERENCES}

1. Burton, A. C. 1954. Relation of structure to function of the tissues of the wall of blood vessels. Physiol. Rev. 34: 619.

2. Remington, J. W. 1955. Hysteresis loop behavior of the aorta and other extensible tissues. Amer. J. Physiol. 180: 83.

3. Roach, M. R., and A. C. Burton. 1957. The reason for the shape of the distensibility curves of arteries. Can. J. Biochem. Physiol. 35: 681.

4. Fukaya, H., C. J. Martin, A. C. Young, and S. Katsura. 1968. Mechanical properties of alveolar walls. J. Appl. Physiol. 25: 689.

5. Stephens, N. L., E. Kroeger, and J. A. Mehta. 1969. Force-velocity characteristics of respiratory airway smooth muscle. J. Appl. Physiol. 26: 685.

6. Wilkie, D. R. 1956. The mechanical properties of muscle. Brit. Med. Bull. 12: 177.

7. Rigby, B. J., N. Hirai, J. D. Spikes, and H. Eyring. 1959. The mechanical properties of rat tail tendon. J. Gen. Physiol. 43: 265.

8. Stromberg, D. D., and C. A. Wiederhielm. 1969. Viscoelastic description of a collagenous tissue in simple elongation. J. Appl. Physiol. 26: 857.

9. Ridge, M. D., and V. Wright. 1966. Mechanical properties of skin: a bioengineering study of skin structure. J. Appl. Physiol. 21: 1602.

10. Fung, Y. C. B. 1968. Biomechanics. Appl. Mech. Rev. 21: 1 .

11. Lipkin, M., T. Almy, and B. M. Bell. 1962. Pressure volume characteristics of the human colon. J. Clin. Invest. $41: 1831$.

12. Christensen, J., and G. F. Lund. 1969. Esophogeal responses to distension and electrical stimulation. J. Clin. Invest. 48: 408 .

13. LaBan, M. 1962. Collagen tissue; implications of its response to stress in vitro. Arch. Phys. Med. 43: 461.

14. Carton, R. W., J. Dainauskas, and J. W. Clark. 1962. Elastic properties of single elastic fibers. J. $A p p l$. Physiol. 17: 547.

15. Hill, A. V. 1949. Is relaxation an active process? Proc. Royal Soc. Ser. B. 136: 420.

16. Fung, Y. C. B. 1967. Elasticity of soft tissues in simple elongation. Amer. J. Physiol. 213: 1532.

17. Starling, E. H. 1918. The Linacre lecture on the law of the heart. Longmans, Green and Co., Ltd. London.

18. Remington, J. W., and R. S. Alexander. 1956. Relation of tissue extensibility to smooth muscle tone. Amer. $J$. Physiol. 185: 302.

19. Zatzman, M., R. W. Stacy, J. Randall, and A. Eberstein. 1954. Time course of stress relaxation in isolated arterial segments. Amer. J. Physiol. 177: 299.

20. Wilkie, D. R. 1956. Measurement of the series elastic component at various times during a single muscle twitch. J. Physiol. (London). 134: 527.

21. Frisen, J., M. Magi, L. Sonnerup, and A. Viidik. 1969. Rheological analysis of soft collagenous tissue. J. Biomechanics. 2: 13.

22. Lee, J. S., W. G. Frasher, and Y. C. Fung. 1968. Comparison of elasticity of an artery in vivo and in excision. J. Appl. Physiol. 25: 799.

23. Brackney, E. L., G. S. Campbell, A. P. Thal, and O. H. Wangensteen. 1955. Spontaneous performation of the esopthagus; experimental study. Proc. Soc. Exp. Biol. Med. 88: 307. 